\title{
Reticence and willingness to communicate (WTC) of East Asian language learners
}

\author{
Qing Shao, Xuesong (Andy) Gao Faculty of Education, The University of Hong Kong, Hong Kong
}

\begin{abstract}
In this virtual special issue editorial, we examine the claims put forward by studies con- cerning East Asian language learners' reticence and willingness to communicate ('WTC') published in System between 2000 and 2015. The selected articles have explored why and how language learners are willing to participate or choose to be reticent in classroom activities in a variety of contexts including Japan, Korea, Mainland China, Hong Kong, Macau, New Zealand, and Taiwan. The findings encourage language teachers to involve East Asian language learners in pedagogical activities as these learners are not culturally conditioned to be silent and passive. The selected articles also remind language teachers of the importance of managing various individual and contextual factors underlying these learners' willingness to communicate in classes. With this editorial, we invite our readers to react to the selected articles and help us deepen engagement with these issues so that we can promote language learners' classroom participation.
\end{abstract}

\section{Introduction}

This paper reviews 10 articles on East Asian language learners' reticence and willingness to communicate (WTC) that were published in System during 2000e2015. Our interest in reviewing these studies has been closely associated with a popular perception about East Asian learners' unwillingness to communicate in classes, or their reticence in the learning process, often constructed as a consequence of the Confucian Heritage Culture (Griffiths et al., 2014). Despite this popular perception having been discredited as a myth, an overgeneralisation or a stereotype (Cheng, 2000; Liu \& Littlewood, 1997), the perception of East Asian learners as passive, reticent and rote learners seems to have survived and is still being discussed and contested in the latest literature (e.g., Hsu, 2015). To understand these students' classroom participation better, it is important to explore how and why they participate. This involves an examination of their WTC, that is, their 'predisposition to initiate or avoid communication with others when given a choice' (Pawlak \& Mystkowska-Wiertelak, 2015, p. 2). As we went through the key words in articles published in the journal in the last decade, WTC emerged as one of the most frequently used keywords. According to Elsevier's ScienceDirect database, 63 articles published in System in the last five years have something to do with the keyword 'willingness to communicate', of which 39 were published in 2014 and 2015. In comparison, 47 articles used this term as a keyword during 2000e2010. For this reason, we invite our readers to access a selection of articles on East Asian language learners' reticence and WTC and help us deepen our engagement with these 
issues. Before we do so, we first examine the issue of East Asian students' reticence in class and then elaborate the increasingly popular concept of WTC in language learning research.

2. East Asian learners' reticence problematized

It is highly problematic to categorise language learners with diverse cultural and social experiences as 'East Asian learners'. We use 'East Asian learners' as a convenient label to refer to language learners from the so-called Confucian Heritage cultural contexts, including countries or regions like China, Hong Kong, Japan, Korea, Macau, and Taiwan (Griffiths et al., 2014). Researchers and practitioners have long noticed that some students from the so-called Confucian Heritage cultural contexts tend to display particular characteristics and behaviours in the learning and teaching process such as obedience to authority, rote learning, fear of negative evaluation and losing face, reticence and passivity (Cao \& Philp, 2006; Kumaravadivelu, 2003; Lee, 2007). Reticence or lack of participation in classroom activities might have been one of the most salient challenges especially for teachers from Western culture because it leads to low classroom participation and causes frustration to teachers (Jackson, 2003). It must be noted that reticence is different from silence. While silence 'represents an indispensable layer of interpersonal discourse and is a natural part of conversational skills,' reticence suggests 'subordination or a potential handicap in activating such communicative skills' (Bao, 2014, pp. 13e14). Therefore, if all second language learners appear to be reticent in classroom activities, teachers do need to address the issue and find ways to cultivate capacity for active participation in the learning process. The question is whether or not East Asian learners' reticence is a myth resulting from long-standing prejudice and hackneyed Eastern-Western stereotypes. For this reason, we invite readers to revisit Cheng (2000)’s article ‘Asian students' reticence revisited.'

This article is among the earliest studies that questioned the stereotype of East Asian second language learners. Cheng (2000) presents two arguments based on his own teaching experience, classroom observations in China and an informal survey. The first argument is about whether Asian students are generally reticent and passive in the learning process and the second concerns whether Asian students' reticence is cultural. Cheng (2000) first problematizes the projection of East Asian learners as passive and reticent 'largely based on the impressions of a small number of teachers or professors registered in small scale surveys, many of which were conducted outside Asian countries' (p. 445). While revisiting this argument 15 years later, it seems that a conclusion in this context can now be drawn confidently since the number of students from East Asian countries pursuing academic studies abroad or undertaking studies in the medium of English in their home contexts has risen exponentially. For instance, in 2014 nearly half-amillion Chinese students went abroad for study, sixty percent of them to the US (Wang \& Shi, 2015). The patterns of their classroom behaviours have been extensively examined and interpreted in research.

Relevant articles published in System have explored classroom participation of East Asian students in general and Chinese students in particular. Jackson (2003), for example, found that some professors from a university in Hong Kong were discouraged by students' reticence in classroom discussions. In her investigation covering 589 business students from the same university, while most students wanted to participate in their mother tongue (Cantonese), periods of awkward silence were common during classroom discussions in English. In Hsu's (2015) most recent study on 354 Taiwanese university freshmen, although students generally valued EFL 
classroom participation and were reluctant to be viewed as passive learners, they demonstrated overall low involvement in classroom communication in the medium of English. Some students reported non-participation. These studies suggest that the claim of passivity and reticence may be true for 'a small number of Asian students' (Cheng, 2000, p. 439) but there are apparently many other reasons that explain their classroom behaviours, apart from being Asian. Apart from the medium of instruction as noted by Jackson (2003) and Hsu (2015), Cheng (2000) argued that observed reticence of students may have something to do with 'unsuitable methodology, lack of required lan- guage proficiency, irrelevant or even offensive topics, lack of rapport between the teacher and the students, lack of motivation and even students' mood' (p. 442).

Consequently, Cheng (2000) further questioned whether East Asian students' passivity and reticence can be attributed to cultural traditions such as influence of the Confucian culture and the highly valued collectivism. He contends that these students' reticence is situation-specific rather than cultural. It must be noted that Confucian Heritage Cultures are outlined as emphasising family loyalty and social harmony to an extent that community's interests usually come first, before individual's (Griffiths et al., 2014). When an individual loses face, it not only results in personal hurt but also a sense of shame for the family or the team; the individual may come to be viewed a black sheep by fellow beings. This might lead to fear of making mistakes in class. Also, for the hierarchical stability of the society, people with authority such as elders and teachers should be respected. These cultural characteristics are often seen as the cause of the reticence among East Asian students (Cortazzi \& Jin, 1996).

Such interpretation reflects influences of cultural value studies in the 1970s and 1980s where cultural values, such as individualism or collectivism, are perceived as the determinant of individuals' behaviour. Recent research has problematized this 'over-generalized view of culture, i.e. members of a cultural group are treated as the same, sharing definable charac- teristics whatever the context maybe' (Zhu, 2016, p. 7). Many researchers in the field of second language teaching and learning also reject simplistic cultural interpretations because they are deemed as stereotyped discourses for 'convenient explanation', ignoring 'vast differences in the thinking styles, behaviours, manners, tastes and world views' underlying any observable behaviours' (Bao, 2014, pp. 6-7; also see; Cheng, 2000; Liu \& Littlewood, 1997).

Nevertheless, it is still important to acknowledge the mediation of particular cultural and educational practices that many East Asian learners have been socialized into on their classroom participation, though it may be desirable to be cautious when interpreting students' classroom behaviours in terms of cultural traditions (e.g. Gao, 2008a \&b). In Chen (2003), a Japanese female student studying in a US university-based ESL class told the researcher that when she was in high school in Japan, there was no academic discussion in class at all. This might be the reason why she avoided brainstorming in the US classroom. Also, she felt it difficult to ask questions in front of the whole class because she was not sure if the question was 'appropriate' (Chen, 2003, p. 267). In this case, the ways the student used to be taught and learned in Japan did profoundly mediate the ways she approached learning in the new context. Therefore, it is necessary to reflect on the findings from a collection of studies on East Asian language learners' reticence and Willingness to Communicate (WTC) for a deeper understanding of the underlying causes of the reticence and to avoid any convenient and overgeneralised explanations. 
3. Willingness to communicate (WTC)

WTC has emerged as a construct for exploring why some people are more reluctant to communicate in the first language (L1) at the very start and it is largely linked to one's personality. This suggests that WTC in L1 is not situation-specific but trait- like. Many quantitative studies have been conducted to investigate what personal characteristics may stimulate or impede communication (e.g., Chan \& McCroskey, 1987; McCroskey, 1992; McCroskey \& Richmond, 1990, 1991). In second language learning research, WTC is conceptualized as 'a readiness to enter into discourse at a particular time with a specific person or persons, using a L2' (MacIntyre, Cle ment, Do rnyei, \& Noels, 1998, p. 547). In contrast to WTC in L1, WTC in L2 appears to be more situation-specific and unlike a trait. Such conceptualisation has been further developed and confirmed in the selection of studies in this special issue. For instance, Cao and Philp (2006) found that factors such as 'group size, familiarity with interlocutor(s), interlocutor(s)' participation, familiarity with topics under discussion, self-confidence, medium of commu- nication and cultural background' work together to influence one's WTC (p. 480). Other studies including Cao (2011) and Peng (2012) have also concluded that WTC is a complicated phenomenon resulting from the interplay of individual and situational factors. These factors include proficiency level, anxiety, social context, confidence, affective dimensions, cognitive conditions, motivation and attitudes, gender, age and so forth (Cao \& Philp, 2006; Pawlak \& Mystkowska-Wiertelak, 2015). These studies project WTC not as a static but as a dynamic construct since the same person's WTC may vary and fluctuate under different conditions; this has been carefully documented and explored in other research underpinned by an ecological perspective on WTC (e.g., MacIntyre \& Legatto, 2011; Mystkowska-Wiertelak \& Pawlak, 2014; MacIntyre, Burns, \& Jessome, 2011; Yu, 2015).

We have noted efforts undertaken by researchers to expand the theoretical underpinning of WTC research. For instance, MacIntyre and Doucette (2010) use Julius Kuhl's action control scale (hesitation, preoccupation and volatility) to expand the conceptual framework of WTC. Like a doctor who refuses to save the patient and a chef who refuses to cook, they contend that an L2 learner who refuses to communicate in L2 and habitually avoids speaking opportunities could also be viewed as someone who fails to act on intention. They suggest that low willingness to communicate has to do with the propensity for disrupting action control, that is, unsatisfactory ability to begin a task resolutely and focus on it until completion. In this article, most of the 233 participants spoke English as mother tongue and were learning French as L2 in Canada. Apart from the theoretical contribution, this study, together with other WTC research, helps better explain East Asian language learners' reticence.

\section{The virtual issue}

Including Cheng (2000) outlined above, the virtual special issue has 10 articles published in System from 2000 to 2015, which, we believe, constitute an ongoing dialogue concerning East Asian language learners' reticence and WTC. First, these studies are not simply 'based on the impressions of a small number of teachers or professors ... outside Asian countries' (p. 445). Given the global mobility of Asian students, we selected studies that were conducted in East Asian countries/regions such as Hong Kong, Korea, Japan, Macau and Taiwan, and on East Asian learners studying in western countries. Second, these studies do not adopt an essentialist approach to culture and treat it as a convenient label to interpret East Asian learners' classroom behaviour. Some of the studies (e.g. Cao, 2011; Peng, 2012; Zhong, 2013) adopted a dynamic 
and situated perspective, which sees cultural traditions as an important dimension of the individual, situational and environmental conditions underlying the phenomenon of reticence and passivity.

Jackson, J. (2003). Case-based learning and reticence in a bilingual context: perceptions of business students in Hong Kong. System, 31(4), 457e469.

Jackson (2003) reports on a three-year investigation covering 589 Asian business students' attitudes towards case-based learning. Questionnaires seeking answers on six-point Likert scales were administered, followed by ethnographic interviews and class observations. Reticence in class discussion emerged from the data as a theme because class observations suggested that periods of silence were common in classroom discussions in English. Most students stated that they were more relaxed when using their mother tongue (Cantonese) in class discussion. When it comes to English usage in classroom, approximately 15\% of the respondents reported difficulties in vocabulary, technical terms and oral fluency. A relatively long period of time for information processing and translations between Chinese and English was mentioned as a cause. The participants were also found to have been reluctant to disagree with their professors though they were more willing to challenge their peers, especially in small groups rather than in front of the whole class. The effort to maintain harmony in classrooms, which sometimes led to the reluctance to talk, reflects the impact of traditional values of Confucian Heritage Cultures on classroom participation.

Hsu, W. H. (2015). Transitioning to a communication-oriented pedagogy: Taiwanese university freshmen's views on class participation. System, 49, 61-72.

Hsu (2015) investigated the attitudes of 354 freshmen in a Taiwanese university towards oral participation in EFL class. It was an attitudinal study and no class observation was conducted. Apart from a questionnaire designed to elicit students' viewpoints, the researcher designed a 4point Likert scale to elicit students' real-life class participation patterns based on self- reporting. It was found that students generally valued EFL classroom participation and did not want to be labelled as passive learners. They, however, reported overall low involvement in classroom communication, which suggested discrepancies between beliefs and behaviours. Very similar to Jackson (2003), communicative barriers were found to constitute the main cause of reticence and long information processing time and Chinese-English translation were also mentioned. The partic- ipants also brought up personality-related reasons such as lack of confidence, fear of speaking in front of the public, shyness and nervousness. More than $50 \%$ of the participants mentioned the fear of losing face when making mistakes. Both studies suggest that these students' reticence in classroom participation is cultural and can be attributed to respect for authoritative figures like professors and unwillingness to loose 'face' in public. They also revealed that the medium of instruction or classroom participation could be another significant cause for the students' reticence.

Kang, D. M. (2014). The effects of study-abroad experiences on EFL learners' willingness to communicate, speaking abilities, and participation in classroom interaction. System, 42, 319-332. From a unique perspective, Kang (2014) focuses especially on the eight weeks' study-abroad (SA) experiences of 60 Korean university students in L1 English-speaking countries and its possible correlation with these students' WTC, oral English proficiency and actual participation in class. The author tracked the performance of the students before and after SA pro- grammes 
by collecting data through the use of questionnaire, language contact profile, WTC in English scale, speaking proficiency interview, classroom observation and post-observation interview. Accordingly, a portfolio of data analysis tools was employed to generate findings, including descriptive analysis, a paired samples t-test, a two-tailed Pearson's correlation, a regression analysis, a one-way analysis of variance (ANOVA) and an analysis of covariance (ANCOVA). Triangulated by interview data, the results suggest that students' WTC developed significantly as a result of SA experiences in English- speaking countries. This development was attributed to integration of contextual factors, learner beliefs and learner au- tonomy. The study then warrants some further inquiries that would contribute to our understanding of students' WTC and to teachers' pedagogical practices. Questions include how to sustain the improved WTC that has to do with the SA experience and whether there is anything transferrable from the SA experience that can shed light on classroom pedagogy to benefit those who do not have a chance to go abroad.

Chen, T. (2003). Reticence in class and on-line: Two ESL students' experiences with communicative language teaching. System, 31(2), 259-281.

In addition to these large scale quantitative studies, qualitative inquiries have also shed light on the underlying factors and reasons behind the observed reticence and passivity. Chen (2003) conducted in-depth interviews with a Japanese and a Korean student learning English in the US and explored possible causes underlying their reticence by interpreting their life history narratives. The study constitutes a unique contribution as it focuses on 'the students' individuality while locating them in their cultural contexts, which is different from many studies that put students into ethnic groups' (Chen, 2003, p. 271). By doing so, the study 'avoids attributing student difficulties simply to ethnic/cultural backgrounds in order not to obscure the intricate nature of the situation' (Chen, 2003). The study offers insights into how prior cultural experiences helped develop particular classroom participation patterns in which the participants 'think deeply before talking' (p. 265) and 'say little rather than too much' (p. 267). Echoing findings from Jackson (2003) and Hsu (2015), Chen (2003) confirms that it is necessary to adopt alternative perspectives when exploring how various cultural, historical and social conditions might mediate East Asian language learners' reticence and WTC.

Eddy-U, M. (2015). Motivation for participation or non-participation in group tasks: A dynamic systems model of task- situated willingness to communicate. System, 50, 43-55.

Through semi-structured focus group interviews, Eddy-U (2015) examined what factors had motivated or demotivated 25 students' WTC in task-related classroom activities such as language games, small-group discussions and group projects. Using Do€rnyei's concept of 'motivational conglomerates' (p. 45), the researcher found that 'interest, perceived effectiveness', good group mates, 'good classroom social situation, personal vision, self-confidence' and marks motivated first-year non-English majors in Macau to communicate in EFL classroom activities. When these individual and sociocultural factors were prob- lematic, students could feel demotivated and become reluctant to participate. Interestingly, the author confirms that the L2 anxiety is not unique to East Asian students but the 'pressure to maintain face' (p. 52) among Chinese and other Asian cultures is still perceived as stronger than elsewhere. The author also presents a model of task-situated WTC based on previous research and her own findings, suggesting that a learner's perceptions of the task and the learner role are more of a WTC predictor than the actual task and learner role themselves are. The pedagogical implication here seems clear that in 
addition to the attention paid to task design, researchers and teachers also need to take learners' perceptions into consideration.

Cao, Y. (2011). Investigating situational willingness to communicate within second language classrooms from an ecological perspective. System, 39(4), 468-479.

Recent articles on WTC have advanced an ecological perspective in which WTC is seen as dynamic and situated as a response to the earlier construct of WTC as a personality-based, traitlike predisposition. Cao (2011) conducted a multiple case study in which a set of qualitative tools, such as class observation, stimulated-recall interviews as well as reflective journals were employed to study students in a language centre based in a university in New Zealand. All but one of the participants were from East Asian countries in Phase II (non-pilot phase) of the study. Since the author did not intend to compare the data about that single participant, Lora, whose mother tongue was German, were not presented in the Results and Discussion. We do not know if she was more or less reticent than her East Asian counterparts. Cao (2011) concludes that 'situational WTC in L2 classrooms emerged from the joint and overlapped effects of individual characteristics including self- confidence, personality, emotion and perceived opportunity to communicate, classroom environmental conditions such as topic, task, interlocutor, teacher and group size, together with linguistic factors' (p. 468). Conclusions akin to Cao (2011) have been drawn by many other researchers in their published works, including Zhong (2013).

Peng, J. E. (2012). Towards an ecological understanding of willingness to communicate in EFL classrooms in China. System, 40(2), 203-213.

Also informed by an ecological understanding of WTC, Peng (2012)'s multiple case study surveyed four students in 2007e08 from a university in southern China over one-and-a-half semesters. Through semi-structured interviews, learning journals recorded by the students and classroom observations, the researcher discovered six factors underlying classroom WTC, including learner beliefs, motivation, cognitive factors, linguistic factors, affective factors and classroom environment. Peng (2012) proposes that 'Chinese EFL students' classroom WTC is socio-culturally constructed as a function of the inter- action of individual and environmental factors, both inside and outside the classroom' (p. 211). In Peng (2012)'s findings we also spot something interesting. Similar to Zhong (2013)'s participants, one of the students in Peng (2012) expressed the same fear of being thought of as 'showing off'. She said to the researcher, in her own words, that 'usually I would answer questions no more than twice. I was concerned that others would think I like to show off, or that I'm always preempting others' (p. 208). Here emerges an issue of anxiety. To clarify, the anxiety here is not L2 anxiety that has to do with confidence in L2 proficiency, but an anxiety about being judged, labelled and then alienated. The student was sufficiently competent to participate in L2 classroom activities but she had to repress her WTC. It seems fair to relate this student's passivity and reticence to her cultural traditions. The fear to be different or unique arguably comes from the Confucian culture, which is characterized by the highly valued collectivism.

Zhong, Q. M. (2013). Understanding Chinese learners' willingness to communicate in a New Zealand ESL classroom: A multiple case study drawing on the theory of planned behaviour. System, 41(3), 740-751.

In settings similar to that in Cao (2011), Zhong (2013) conducted a multiple case study to examine five Chinese immigrant learners of English in teacher-centered and collaborative 
learning activities and found support for the argument that WTC is situational and contextdependent. In a series of in-depth interviews, classroom observations, stimulated recall interviews and learning logs, students' reticence was discovered to be 'related to a mixture of linguistic, affective and socio-cultural factors as shown in other previous studies' (p. 749). Among these factors, concerns for accuracy was found to be the most influential factor that impeded speaking up in class. This can be associated to the issue of fear of losing face that the author found among these learners as well, since making mistakes could be perceived by East Asian students as face-losing. Similar to Eddy-U (2015), learners' self-perception was found to affect WTC. According to Zhong (2013)'s observations, students who were unwilling to communicate 'did not perceive themselves as having the competence to speak up with ease in front of others' (p. 745). One of those learners did perceive herself as proficient enough. However, she chose not to participate because she was afraid of her participation being perceived as showing off by her peers. These findings of Zhong (2013) suggest that the impression of East Asian students' reticence and passivity clearly did not come out of nowhere. Although it could not be simply reduced to stereotypes, cultural dimensions do have an impact on the WTC of these learners.

Subtirelu, N. (2014). A language ideological perspective on willingness to communicate. System, 42, 120-132.

Finally, Subtirelu (2014) argues that L2 users' perceptions of their communicative competencies, an important aspect of WTC, are closely related to their own L2 communication experiences while the relationship between the two 'is mediated by language ideology' (Subtirelu (2014), p. 120). Exploring the language attitudes and ideologies of students studying English at a US university, the author focused on three adult students e 1 from China and 2 from Saudi Arabia. Two different language ideologies, namely, the deficit ideology and the lingua franca ideology, were identified. One of the Saudi students drew on the lingua franca ideology and portrayed himself as a competent L2 communicator. In contrast, the Chinese participant demonstrated deficit ideology in which he thought poorly of his proficiency in English language. In the study he admitted that he had very little communication with US students since his spoken English was not proficient enough to make himself understood every time. This finding suggests that individual language learners' ideological beliefs and perceptions of their own positioning as language learners also matter in mediating their willingness to communicate and participate in socialisation through language use.

\section{Conclusion}

The collection of studies in this virtual special issue show that East Asian language learners' reticence and WTC cannot be solely accounted for by cultural reasons and have to be understood in relation to a variety of cultural, historical and social conditions and processes. The findings are highly encouraging for language teachers who may feel exasperated with some East Asian language learners' reticence in language classrooms as they show that these learners are not culturally conditioned to be silent and passive. They also remind language teachers that language learners' willingness to communicate in language classes emerges from the interaction of various individual and contextual factors. Meanwhile, the cultural factor does constitute one of the factors that have some impact on students' WTC and thus cannot be overlooked or merely reduced to stereotypes. Further efforts are needed to transform these findings into pedagogical principles that can help enhance language learners' learning through active participation in 
language classroom activities. It is also desirable for language teachers and researchers to reflect on whether reticence is necessarily a negative and WTC a positive sign of learning. In language teaching, active participation has been promoted as both the goal and the means by which language learners improve and become communicatively competent. Such approach to teaching might have neglected the fact that language learners have diverse goals in learning and there are also different ways to help learners achieve their goals through teaching. Surely it is necessary for language teachers to have an appropriate understanding of language learners' reticence and WTC, but it is more important for us to learn how to ensure learning happens even when our language learners appear to be reticent in classes.

\section{References}

Bao, D. (2014). Understanding silence and reticence: Ways of participating in second language acquisition. London: Bloomsbury.

Cao, Y. (2011). Investigating situational willingness to communicate within second language classrooms from an ecological perspective. System, 39(4), 468-479.

Cao, Y., \& Philp, J. (2006). Interactional context and willingness to communicate: A comparison of behavior in whole class, group and dyadic interaction. System, 34(4), 480-493.

Chan, B. M., \& McCroskey, J. C. (1987). The WTC scale as a predictor of classroom participation. Communication Research Reports, 4, 47-50.

Chen, T. (2003). Reticence in class and on-line: Two ESL students' experiences with communicative language teaching. System, 31(2), 259-281.

Cheng, X. (2000). Asian students' reticence revisited. System, 28(3), 435-446.

Cortazzi, M., \& Jin, L. (1996). Cultures of learning: language classrooms in China. In Coleman, H. (Ed.), Society and the Language Classroom (pp. 169-206). Cambridge: Cambridge University Press.

Eddy-U, M. (2015). Motivation for participation or non-participation in group tasks: A dynamic systems model of task-situated willingness to communicate. System, 50, 43-55.

Griffiths, C., Oxford, R. L., Kawai, Y., Kawai, C., Park, Y. Y., Ma, X., \& Yang, N. D. (2014). Focus on context: narratives from East Asia. System, 43, 50-63.

Hsu, W. H. (2015). Transitioning to a communication-oriented pedagogy: Taiwanese university freshmen's views on class participation. System, 49, 61-72.

Jackson, J. (2003). Case-based learning and reticence in a bilingual context: perceptions of business students in Hong Kong. System, 31(4), 457-469.

Kang, D. M. (2014). The effects of study-abroad experiences on EFL learners' willingness to communicate, speaking abilities, and participation in classroom interaction. System, 42, 319-332.

Kumaravadivelu, B. (2003). Problematizing cultural stereotypes in TESOL. TESOL Quarterly, 37(4), 709-719.

Lee, E. L. (2007). Linguistic and cultural factors in East Asian students' oral participation in US university classroom. International Education, 36(2), 27. 
Liu, N. F., \& Littlewood, W. (1997). Why do many students appear reluctant to participate in classroom learning discourse?. System, 25(3), 371-384.

MacIntyre, P. D., Burns, C., \& Jessome, A. (2011). Ambivalence about communicating in a second language: a qualitative study of French immersion students' willingness to communicate. The Modern Language Journal, 95(1), 81-96.

MacIntyre, P.D., Cle' ment, R., Do“"rnyei, Z., Noels, K.A. (1998). Conceptualizing willingness to communicate in a L2: a situational model of L2 confidence and affiliation. The Modern Language Journal, 82, 545-562.

MacIntyre, P. D., \& Doucette, J. (2010). Willingness to communicate and action control. System, 38(2), 161-171.

MacIntyre, P. D., \& Legatto, J. J. (2011). A dynamic system approach to willingness to communicate: developing an idiodynamic method to capture rapidly changing affect. Applied Linguistics, 32(2), 149-171.

McCroskey, J. C. (1992). Reliability and validity of the willingness to communicate scale. Communication Quarterly, 40(1), 16-25.

McCroskey, J. C., \& Richmond, V. P. (1990). Willingness to communicate: differing cultural perspectives. Southern Communication Journal, 56, 72-77.

McCroskey, J. C., \& Richmond, V. P. (1991). Willingness to communicate: a cognitive view. In M. Booth-Butterfield (Ed.), Communication, cognition, and anxiety (pp. 19-37). Newbury Park, CA: Sage.

Mystkowska-Wiertelak, A., \& Pawlak, M. (2014). Fluctuations in learners’ willingness to communicate during communicative task performance: Conditions and tendencies. Research in Language, 12(3), 245-260.

Pawlak, M., \& Mystkowska-Wiertelak, A. (2015). Investigating the dynamic nature of L2 willingness to communicate. System, 50, 1-9.

Peng, J. E. (2012). Towards an ecological understanding of willingness to communicate in EFL classrooms in China. System, 40(2), 203-213.

Subtirelu, N. (2014). A language ideological perspective on willingness to communicate. System, 42, 120-132.

Wang, Y., \& Shi, R. (2015, March 6). Number of study-abroad students 2014 increased to approximately 460 thousand. Caixin Media. Retrieved from http://china.caixin.com/201503-06/100788923.html

Yu, M. (2015). An examination of the dynamic feature of WTC through dyadic group interaction. System, 55, 11-20.

Zhong, Q. M. (2013). Understanding Chinese learners' willingness to communicate in a New Zealand ESL classroom: A multiple case study drawing on the theory of planned behavior. System, 41(3), 740-751.

Zhu, H. (2016). Identifying Research Paradigms. In H. Zhu (Ed.), Research Methods in Intercultural Communication: A Practical Guide. (pp1-22). Rawang: Wiley Blackwell. 